\title{
Structural Study for a New Superconducting Phase in the Bi-Sr-Cu-O System
}

\author{
Kazumasa Sugiyama and Yoshio Waseda \\ Research Institute of Mineral Dressing and Metallurgy (SENKEN), \\ Tohoku University, Sendai 980, Japan \\ Keiji Moroishi*, Akihisa Inoue, and Tsuyoshi Masumoto \\ Institute for Materials Research, Tohoku University, Sendai 980, Japan
}

Z. Naturforsch. 43a, 517-520 (1988); received March 13, 1988

A structural identification of the superconducting phase in the $\mathrm{Bi}-\mathrm{Sr}-\mathrm{Cu}-\mathrm{O}$ system has been carried out by X-ray and electron diffraction. A lamellar oxide structure expressed by the formula $\mathrm{Bi}_{2}(\mathrm{Bi}, \mathrm{Sr})_{2} \mathrm{CuO}_{x}$ with the orthorhombic $a=0.537 \mathrm{~nm}, b \simeq 5 \cdot 0.537 \mathrm{~nm}$ and $c=2.463 \mathrm{~nm}$ (pseudotetragonal subcell $a=0.5369(1) \mathrm{nm}$ and $c=2.4627(5) \mathrm{nm}$ ) is found to be responsible for the superconductive property. The structural model of this compound is compared with the Aurivillius phases.

\section{Introduction}

After the spectacular discovery of a superconducting phase of the La-Ba-Cu-O system, having the $\mathrm{K}_{2} \mathrm{NiO}_{4}$ structure, by Bednortz and Müller [1], an even superior superconductor, whose superconducting transition temperature exceeds the liquid nitrogen temperature, was found in the $\mathrm{Y}-\mathrm{Ba}-\mathrm{Cu}-\mathrm{O}$ system, $[2,3]$. The $\mathrm{Y}-\mathrm{Ba}-\mathrm{Cu}-\mathrm{O}$ type superconductor is a derivative of the ordered oxygen deficient perovskite structure, which is formed by corner-sharing $\mathrm{CuO}_{5}$ and $\mathrm{CuO}_{4}$ polyhedra linked with yttrium layers [4]. The superconductive phenomena in the $\mathrm{Y}-\mathrm{Ba}-\mathrm{Cu}-\mathrm{O}$ system seem to be due to defective oxygen sites caused by the mixed valence of copper, although the superconducting mechanism is not yet understood. Knowledge of other oxide superconductors and their structure is needed in order to clarify the superconducting phenomena in these oxides.

Some previous work [5-7] indicated a new superconductive phase in the $\mathrm{Bi}-\mathrm{Sr}-\mathrm{Cu}-\mathrm{O}$ system. It is the main purpose of this paper to determine the structure of this superconducting phase by X-ray and electron diffraction.

\section{Experimental}

Powders of reagent-grade $\mathrm{SrCO}_{3}, \mathrm{Bi}_{2} \mathrm{O}_{3}$ and $\mathrm{CuO}$ were mixed in the desired cation ratio, pre-sintered at $1073 \mathrm{~K}$ for two hours in air and crashed. After twofold

Reprint requests to Dr. K. Sugiyama, Research Institute of Mineral Dressing and Metallurgy (SENKEN), Tohoku University, Sendai 980, Japan. repetition of these treatments the mixtures were pelletized (diameter $10 \mathrm{~mm}$, thickness 1 or $2 \mathrm{~mm}$ ). Subsequently the pellets were sintered at $1073 \mathrm{~K}$ for 18 hours in air and cooled down to room temperature. The electrical resistivity was measured by the fourpoint method. The procedures for synthesizing the samples and the range of superconducting compositions were reported in [5]. The synthesized sample of the nominal composition of $\mathrm{Bi}_{3} \mathrm{Sr}_{3} \mathrm{Cu}_{2} \mathrm{O}_{x}$ was found to exhibit superconductivity with an onset temperature of about $8.5 \mathrm{~K}$, zero resistivity being reached at $5.0 \mathrm{~K}$. This black-colored sample showed mica-like appearance, indicating that its structure is closely related to the mixed bismuth oxides with layered structure (frequently called the Aurivillius phase) $[7,8]$. Powder X-ray diffraction was done with a RIGAKU RAD-B system and electron diffraction with a JEOL $100 \mathrm{CX}$ transmission electron microscope.

\section{Results and Discussion}

The X-ray diffraction pattern of almost pure superconducting $\mathrm{Bi}_{3} \mathrm{Sr}_{3} \mathrm{Cu}_{2} \mathrm{O}_{x}$ is shown in Figure 1. It can be indexed by a pseudo-tetragonal cell with the cell parameters $a=0.5369(1) \mathrm{nm}$ and $c=2.4627(5) \mathrm{nm}$. The cell parameters were determined using fifteen measured $2 \theta$ values and the wavelength of $\mathrm{Cu} \mathrm{K} \alpha_{1}$ $(\lambda=0.15405 \mathrm{~nm})$. Good agreement between the observed and calculated d-spacings is obtained, as

* Present address, Research and Development Laboratories, Hoya Corporation, Akishima, Tokyo 196, Japan.

0932-0784/88/0600-0517 \$01.30/0. - Please order a reprint rather than making your own copy. 


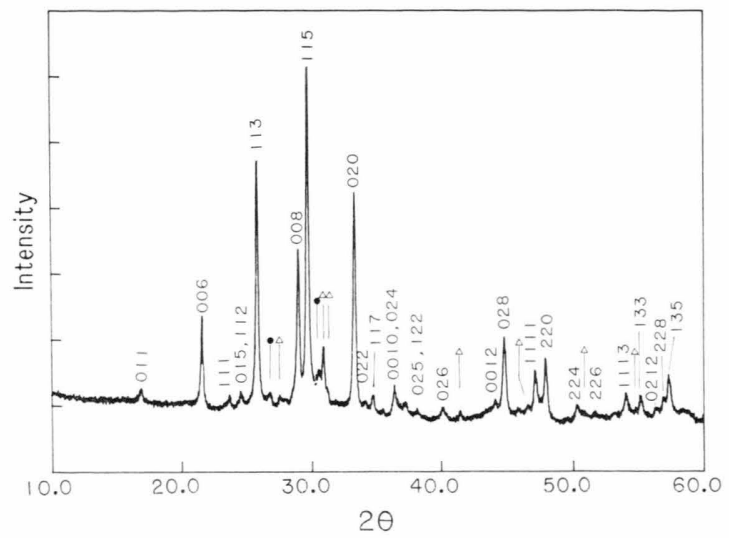

Fig. 1. X-ray powder pattern of $\mathrm{Bi}_{3} \mathrm{Sr}_{3} \mathrm{Cu}_{2} \mathrm{O}_{x}$ synthesized at $1073 \mathrm{~K}$ and annealed in the furnace to room temperature. Pseudo-tetragonal indices are given. $\triangle$ and $\bullet$ indicate, respectively, the presence of $\mathrm{SrCu}_{2} \mathrm{O}_{3}$ and another layered oxide with cell parameters $a=0.5417 \mathrm{~nm}$ and $c=4.968 \mathrm{~nm}$.

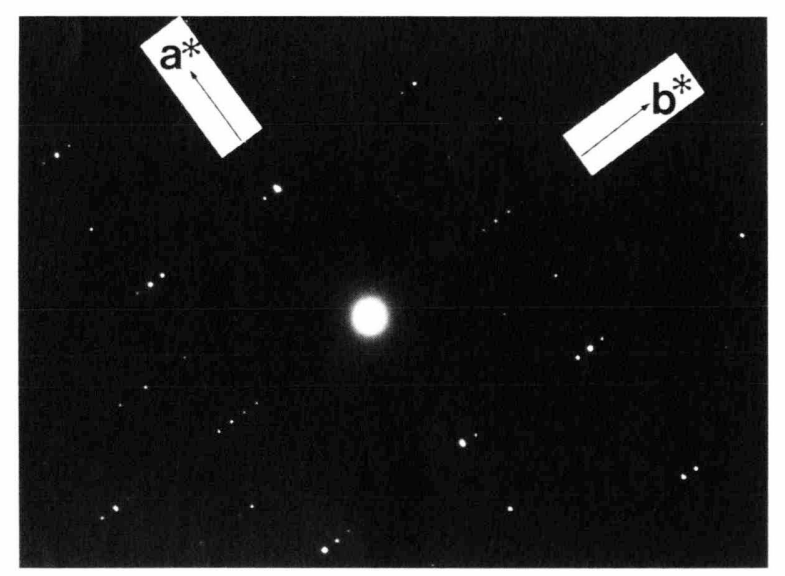

Fig. 2. Electron diffraction pattern corresponding to the plane [001] showing the perovskite subcell.

shown in Table 1. The $a$-axis is considered to be related to cubic perovskite $a_{\mathrm{p}}$ by $\sqrt{2} a_{\mathrm{p}}$. The following two phases were also identified: orthorhombic $\mathrm{Cu}_{2} \mathrm{SrO}_{3}$ with cell parameters $a=0.573 \mathrm{~nm}$, $b=1.341 \mathrm{~nm}$ and $c=0.628 \mathrm{~nm}$, and a pseudotetragonal phase with cell parameters $a=0.542 \mathrm{~nm}$ and $c=4.968 \mathrm{~nm}$. The latter phase appeared to be dominant in oxide mixture with the nominal composition of $\mathrm{Bi}_{4} \mathrm{Sr}_{6} \mathrm{Cu}_{5} \mathrm{O}_{x}$.

Figure 2 shows the electron diffraction pattern of this superconducting phase. A superstructure with the b-cell dimension being about 5 times the periodicity of the $a$-axis is detected, although its periodicity differs slightly from grain to grain. Thus, a feasible cell of this superconducting phase should be orthorhombic with
Table 1. Observed and calculated $d$-spacings of the superconductor. Pseudo-tetragonal cell with $a=0.5369(1) \mathrm{nm}$ and $c=2.4627(5) \mathrm{nm}$.

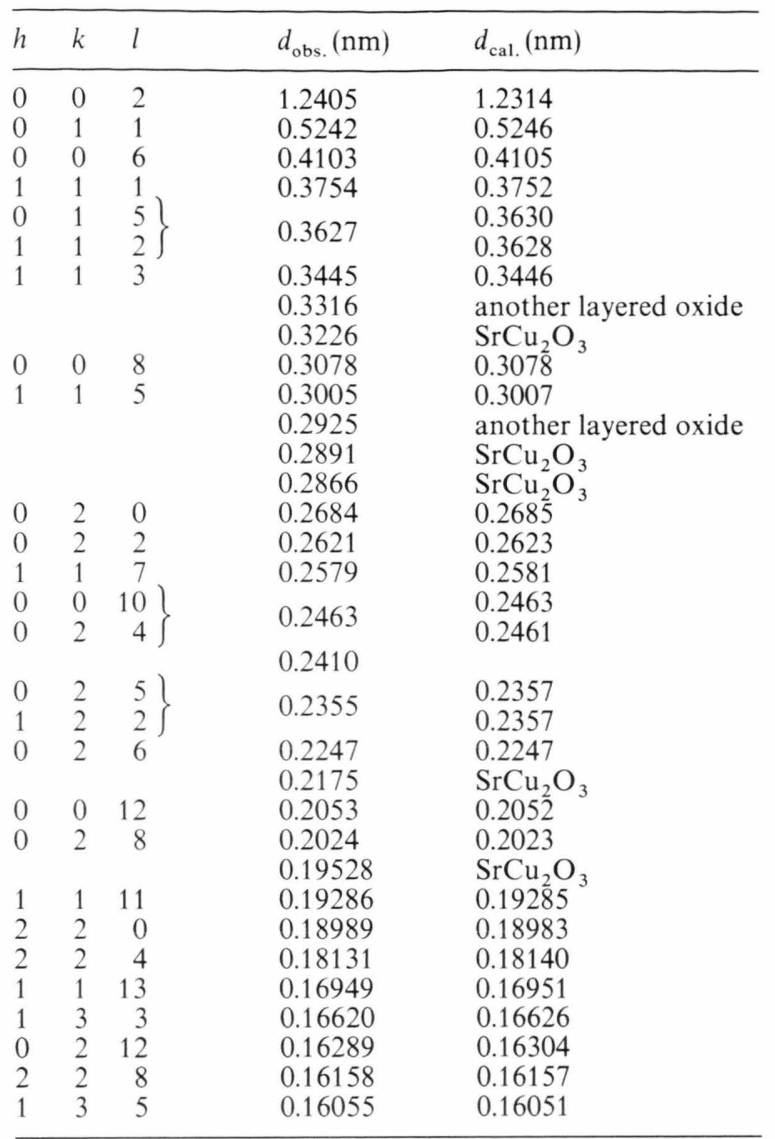

cell parameters $a=0.537 \mathrm{~nm}, b \simeq 5 \cdot 0.537 \mathrm{~nm}$ and $c=2.463 \mathrm{~nm}$. The superstructure is possibly caused by the ordering of the cations and oxygen vacancies together with displacements of the atoms.

The same oxide mixture, when melted and subsequently quenched from high temperature, does not show superconduction. Therefore an oxygen deficient structure caused by the valence change of the cation plays an important role for the superconducting property of the Bi-Sr-Cu-O system, as is also the case for the $\mathrm{Y}-\mathrm{Ba}-\mathrm{Cu}-\mathrm{O}$ system. The sintered sample of the nominal composition of $\mathrm{Bi}_{3} \mathrm{Sr}_{2} \mathrm{Cu}_{5} \mathrm{O}_{x}$ was found to be a mixture of monoclinic $\mathrm{CuO}$ and a pseudo-tetragonal phase with different cell parameters ( $a=0.5406(2) \mathrm{nm}$ and $c=2.446(1) \mathrm{nm}$ ); this oxide mixture exhibits no superconduction. There is a solid solution range regarding the $\mathrm{Sr} / \mathrm{Bi}$ ratio in the pseudo-tetragonal phase, and superconduction is found to occur in a 


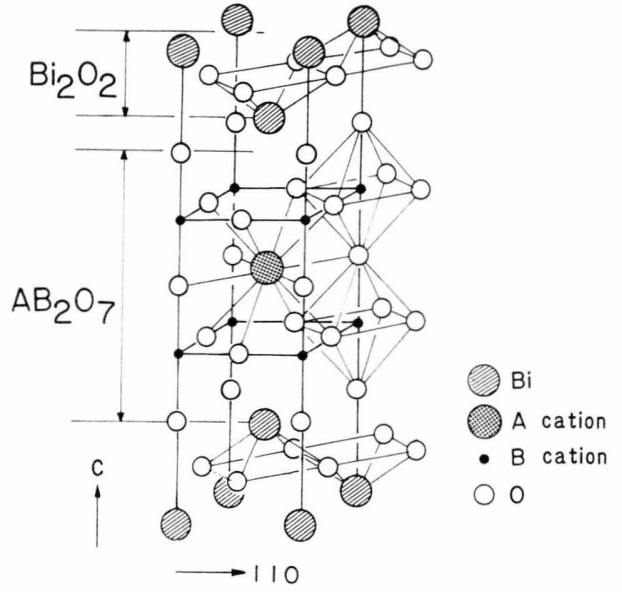

Fig. 3. One-half of the crystal structure of the Aurivillius phase $\mathrm{Bi}_{2} \mathrm{O}_{2}+\mathrm{AB}_{2} \mathrm{O}_{7}$.

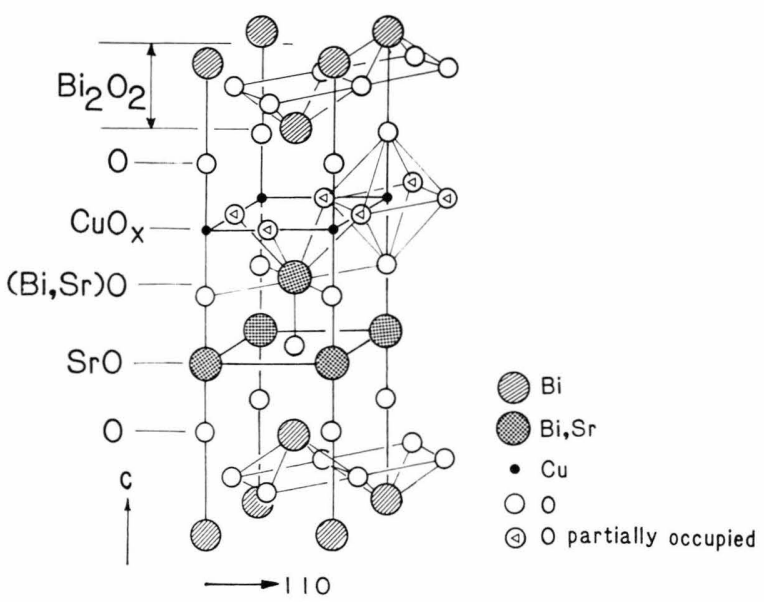

Fig. 4. One-eight of the crystal structural model of superconducting $\mathrm{Bi}_{2}(\mathrm{Bi}, \mathrm{Sr})_{2} \mathrm{CuO}_{x}$.

particular chemical composition range in the $\mathrm{Bi}-\mathrm{Sr}$ $\mathrm{Cu}-\mathrm{O}$ system, similar to the $\mathrm{BaPb}_{1-x} \mathrm{Bi}_{x} \mathrm{O}_{3}$ case previously investigated by Khan et al. [9].

The cell parameters and the mica-like appearance indicate that the structure of the superconducting phase in the Bi-Sr-Cu-O system may be attributed to the layered structure of the Aurivillius phase $\mathrm{Bi}_{2} \mathrm{O}_{2}+\mathrm{AB}_{2} \mathrm{O}_{7}$ illustrated in Fig. 3, where A and $\mathrm{B}$ correspond to large and small cations in the perovskite layer, respectively. An electron probe microanalysis (EPMA) using HITACHI X-650S for the present superconducting phase, however, indicated a possible chemical composition with about $(\mathrm{Bi}, \mathrm{Sr})$ : $\mathrm{Cu}=4: 1$, where the $\mathrm{Bi}$ content is somewhat larger than the $\mathrm{Sr}$ content. This result can not be explained by a model of the Aurivillius phase because the $\mathrm{Sr}$ atoms can not occupy the layered $\mathrm{Bi}$ sites. In addition, the experimental cell parameters of the pseudotetragonal $a$-axis do not comply with $\mathrm{Bi}$ atoms replacing the deficient octahedral sites.

On the other hand, this inconsistency can be dispelled by considering a $\mathrm{SrO}$ layer with a rock-salt type structure instead of the octahedral layer between the Aurivillius $\mathrm{Bi}_{2} \mathrm{O}_{2}$ layers, as shown in Figure 4. It should also be noted in Fig. 4 that the $\mathrm{SrO}$ layer is possibly exchanged by the $\mathrm{CuO}_{x}$ layer. The present model is consistent with the previous work by Takayama-Muromachi et al. [10]. The density of the sample, as measured by the Archimedes method with toluene, was $7.03 \mathrm{Mg} / \mathrm{m}^{3}$, which agrees well with the calculated value of $7.05 \mathrm{Mg} / \mathrm{m}^{3}$, assuming the chemical composition $\mathrm{Bi}_{2} \mathrm{Sr}_{2} \mathrm{CuO}_{6}$.

The chemical composition of this superconducting phase and the feasible structural model of Fig. 4 suggest that part of the $\mathrm{Sr}$ atoms in the rock-salt layer are substituted by $\mathrm{Bi}$ atoms, resulting in the effect on the oxygen distribution around the $\mathrm{Cu}$ sites which is strongly related to the superconducting behaviour. The cation repulsion along the $c$-axis is likely to be relaxed by the degree of occupation of the oxygen sites between the rock-salt layer and the Aurivillius $\mathrm{Bi}_{2} \mathrm{O}_{2}$ layer resulting from the substitution of $\mathrm{Bi}$ atoms for $\mathrm{Sr}$ atoms in the rock-salt type layer. Thus the decrease in the $c$-axis of the pseudo-tetragonal phase contributes to the oxygen deficiency and cation distribution of this structure.

Some further experiments, particularly to determine the oxygen distribution and the solubility range regarding to the $\mathrm{Bi} / \mathrm{Sr}$ ratio are desirable for the exact description of the superconducting phase in this Bi-Sr$\mathrm{Cu}-\mathrm{O}$ system. Nevertheless, the present authors maintain the view that the results of this work represent a step forward towards the structural identification of this oxide system and provide information for a better understanding of the particular superconducting phenomena in the high temperature oxide superconductors.

\section{Acknowledgement}

The authors wish to thank Prof. M. Tokonami, Dr. H. Mori, and O. Tachikawa of the University of Tokyo for their discussion and supporting of the electron microscopic study. They also thank Y. Sato for his technical assistance of the EPMA. 
[1] J. G. Bednorz and K. A. Müller, Z. Phys. B-Condensed Matter 64, 189 (1986).

[2] M. K. Wu, J. R. Ashburn, C. J. Torng, P. H. Hor, R. L. Meng, L. Gao, Z. J. Huang, Y. Q. Wang, and C. W. Chu, Phys. Rev. Lett. 58, 405 (1987).

[3] F. Izumi, H. Asano, T. Ishigaki, A. Ono, and F. P. Okamura, Japanese J. Appl. Phys. 26, L 608 (1987).

[4] C. Michel, M. Hervieu, M. M. Borel, A. Grandin, F. Deslandes, J. Provost, and B. Raveau, Z. Phys. B-Condensed Matter 68, 421 (1987).

[5] K. Moroishi, A. Inoue, K. Matsuzaki, and T. Masumoto, J. Mater. Sci. 23 (1988).
[6] J. Akimitsu, A. Yamazaki, H. Sawa, and H. Fujiki, Japanese J. Appl. Phys. 26, L 2080 (1987).

[7] B. Aurivillius, Arkiv Kemi. 1, 463 (1949).

[8] E. C. Subbarao, J. Amer. Ceram. Soc. 45, 166 (1962).

[9] Y. Khan, K. Nahm, M. Rosenberg, and H. Willner, Phys. Stat. Sol. (a) 39, 79 (1977).

[10] E. Takayama-Muromachi, Y. Uchida, A. Ono, F. Izumi, M. Onoda, Y. Matsui, K. Kusuda, S. Takekawa, and K. Kato, Japanese J. Appl. Phys. 27, 365 (1988). 